\title{
Studies on Seed Germination and Seedling Emergence of Mesquite, Prosopis juliflora (Swartz) DC. in Sudan Gezira
}

\author{
Abubaker M.A. Morgan ${ }^{1}$, Abdalla M. Hamdoun², Nabil H.H. Bashir ${ }^{1, *}$ \\ ${ }^{1}$ Department of Pesticides \& Toxicology, Faculty of Agricultural Sciences, University of Gezira, Sudan \\ ${ }^{2}$ Department of Crop Protection, Faculty of Agricultural Sciences, University of Gezira, Sudan
}

Copyright $\mathrm{C} 2017$ by authors, all rights reserved. Authors agree that this article remains permanently open access under the terms of the Creative Commons Attribution License 4.0 International License

\begin{abstract}
Mesquite, Prosopis juliflora (Swartz) DC, was introduced in many semi-arid areas of Sudan to combat desertification and provide fuel wood and fodder. However, it spread rapidly into fertile, productive areas, and irrigation and drainage channels, particularly in some of the major irrigated schemes. Nursery experiments were conducted at the Faculty of Agricultural Sciences, University of Gezira, Wad Medani, Sudan, to investigate water uptake by seeds, germination-rate, sowing depth, acid scarification and animal feeding of intact pods on germination and seedling emergence. Pods were collected from town, or the National Tree Seed Center laboratory. Seeds were used immediately after extraction. Petri-dishes with filter paper or plastic pots were used. Treatments were arranged in CRB design, with 4-6 replicates. Data were subjected to ANOVA and DMRT. The results revealed that the seeds have high ability to absorb water and exhibited high rate of germination, especially in the second wk after sowing (96\%). Seeds placed on the soil surface failed to germinate, while those buried at depths of $2.5,5,7.5$ and $10 \mathrm{~cm}$ displayed 100, 75, 60 and $40 \%$ germination, respectively. Seedling emergence was delayed by deep burial and amounted to 100 and $50 \%$ at depth of 2.5 and $5 \mathrm{~cm}$, respectively. Seeds germinated and seedlings have emerged at high rates $(100 \%)$, when treated with sulfuric acid $(60 \% \mathrm{v} / \mathrm{v})$ for $5 \mathrm{~min}$. they germinated and seedlings emerged normally, when extracted from sheep droppings.
\end{abstract}

Keywords Mesquite, Prosopis juliflora, Seed Germination, Imbibition, Seedling Emergence, Acid Scarification, Animal Feeding Effect

\section{Introduction}

The genus Prosopis (mesquite), belongs to the family Leguminosae, sub-family Mimosoideae. At least 44 species have been described, and there is still much confusion over the taxonomy of the genus. Most species are native to the Americas, ranging from the southwestern USA, through Mexico and Central America into South America, as far as Argentina. It was then introduced to Australia, Dominican Republic, India, Venezuela, Iraq and the Sudan. At least three species, viz. P. glandulosa Torr., P. juliflora (Swartz) DC. and $P$. ruscifolia Gris., are aggressive woody weeds that cause major problems in grass land. Most species require at least $250 \mathrm{~mm}$ annual rainfall, but some have been found in areas with $<100 \mathrm{~mm}$. P. juliflora is a shrub native to Mexico, South America and the Caribbean. It is fast growing nitrogen-fixing and tolerant to arid conditions and saline soils. The shrub is known to hold the record for depth of penetration by roots. $P$. juliflora roots were found growing at a depth of $53.3 \mathrm{~m}$ at an open-pit mine near Tucson, Arizona. Study conducted by Elfadle and Luukkanen (2006) ${ }^{[1]}$ suggest that the root system has allelopathic and allelochemical effects that inhibits the germination and spread of other plant species. Reports from the South American Center of Diversity revealed that mesquite survives and flourishes in heavy or sandy soils, as well as saline dry flats. Mesquite can tolerate drought and grazing. Some Argentine germplasm $(2 \mathrm{n}=28,52,56,112)$ tolerated mild frost at $40^{\circ} \mathrm{S}$ latitude ${ }^{[2,}$ 3]. The distribution probably ranges from Tropical Thorn through Sub-tropical Thorn to Dry Forest Life Zones (with little frost). Mesquite is reported to tolerate an annual precipitation of 150 to $1670 \mathrm{~mm}$, annual temperature of 20.3 to $28.5^{\circ} \mathrm{C}$, and $\mathrm{pH}$ around neutral ${ }^{[4]}$.

In the Sudan, Prosopis spp were introduced in many semi-arid areas, to combat desertification and provide fuel wood and fodder ${ }^{[5]}$. However, this species have spread rapidly into fertile, productive areas, and irrigation and drainage channels, particularly in some of the major irrigated schemes like Zeidab, New Halfa and Gash Delta, Gezira, Khartoum, etc. Invading $P$. juliflora tends to form dense, impenetrable thickets, associated with unfavorable impacts on human economic activities. In addition, it suppresses the growth of other plant species by denying the plants the most 
valuable growth factors, light and water. In northern Sudan (Gash delta of the Atbara River), the land has been almost completely taken over by $P$. juliflora ${ }^{[6]}$. Similarly, in the Awash basin of Ethiopia, it is aggressively invading pastoral areas in the Middle and Upper Awash Valley, and Eastern Harerge. It is one of the three top priority invasive species in Ethiopia, Sudan and Kenya and has been declared a noxious weed. Sudan has passed a law to eradicate it $^{[7]}$. Moreover, it has already infested large tracts of land in the industrial and residential areas. The same trend was reported in other countries by El-Keblawy and Al-Rawai ${ }^{[8]}$, Rout and Callaway ${ }^{[9]}$.), Inderjit et a ${ }^{[10]}$.

Information on the biology of $P$. juliflora in the Sudan is rather limited, despite its potential hazard as a noxious weed. The objectives of this investigation are to study some factors affecting mesquite seed germination and emergence

\section{Material and Methods}

\section{Collection of Pods}

The experiments undertaken in this study included germination aspects and seedling growth, as influenced by soil and environmental factors. All experiments were conducted under laboratory or nursery conditions at the Faculty of Agricultural Sciences, University of Gezira, Nesheshiba, Wad Medani, Sudan.

Pods were collected from Wad Medani area, Gezira state, Central Sudan, or brought from the National Tree Seed Center laboratory (NTSCL), Soba, Khartoum state. The pods were kept in paper bags and stored under laboratory conditions until needed. Seeds were extracted from pods (using sharp scissors), and used immediately after extraction. In all experiments, unless stated otherwise, Gezira soil was used. The soil was sieved through a $2 \mathrm{~mm}$ mesh screen. Gezira soil is characterized by containing $15 \%$ sand, $32.5 \%$ silt, $52 \%$ clay and $0.5 \%$ organic matter with PH $7.8^{[11]}$. Petridishes $(6 \mathrm{~cm}$ i.d) with similar size filter paper were used in water uptake (WU), i.e. imbibition, germinate- rate (GR) and seed treatment/scarification (ST) experiments. Plastic pots $(14 \mathrm{~cm}$ in height and $13 \mathrm{~cm}$ i.d.) with drainage holes at their bottom were employed in seedling emergence (SE) experiments, i.e. seed burial depth (SBD), and STs. Treatments were arranged in complete randomized block (CRB) design, with 4-6 replicates. Data, unless stated otherwise, were subjected to ANOVA and Duncan's Multiple Range Test (DMRT). Details of individual experiments are given below.

\section{Water Uptake (Imbibition) by Seeds}

An experiment was conducted under laboratory conditions during April. Seeds (50) were, as mentioned earlier, placed on filter paper in Petri-dishes. The filter paper was moistened with $2.5 \mathrm{ml}$ of distilled water (DW), and incubated in the dark (Ali, 1998). Seeds were weighed before moistening, and re-weighed after incubation for 1, 2, 3, 4, 5, 6, 12, 18, 24, 48 and $72 \mathrm{hr}$. WU was expressed as \% of the dry-weight (D.wt.) of seeds.

\section{Germination (G) and Germination-rate (GR)}

$P$. juliflora seeds (10) were treated as above in the Petri-dishes and were examined for germination daily for a period of 14 days. Germination was expressed as percentage of the total number of incubated seeds.

\section{Effect of Sowing Depth (SD) on Seed Germination (SG) and Seedling Emergence (SE)}

Seeds were placed on the soil surface or planted at 2.5, 5.0, $7.5,10.0,20.0$ and $30.0 \mathrm{~cm}$ depth. The pots were irrigated every $24 \mathrm{hr}$. Germinating seeds and emergence of seedlings were counted daily and expressed as percentage of the total number of planted seeds.

\section{Effect of Acid Scarification and Sheep Feeding on Seed Germination (SG) and Seedling Emergence (SE)}

Seeds were soaked in concentrated $\mathrm{H}_{2} \mathrm{SO}_{4}(60 \% \mathrm{v} / \mathrm{v})$ for 5 min and washed in running tap water for another $5 \mathrm{~min}$. Treated and untreated seeds (5 each) were placed in Petri dishes, as above, and tested for germination. Moreover, seeds $(5 / \mathrm{pot})$ were planted at $2.5 \mathrm{~cm}$ depth. Emerged seedlings were counted daily for 15 days. Untreated seeds were included as controls.

Three sheep were fed intact pods, beside their normal diet. Seeds were extracted from droppings after $24-36 \mathrm{hr}$ and washed with tap water. These seeds were subjected to the above-mentioned germination and emergence tests. The control seeds were those obtained from normal pods.

\section{Results}

\section{Water Uptake (Imbibition) by Seeds}

Weight of moistened seeds of $P$. juliflora gradually increased with time during the first $18 \mathrm{hr}$ after incubation. However, the increase was not significant. A surge in seed weight took place during the period 18-24 $\mathrm{hr}$, and then slowly increased for the rest of the incubation period. Significant differences in seed weight were revealed $24-72 \mathrm{hr}$ after incubation (Table 1). The results showed that the seed weight increased by $18.5 \%$ in 3 days.

Water imbibition by seed followed the same trend as seed weight. Imbibition progressively increased with incubation period and maximum WU was attained $48-72 \mathrm{hr}$ after incubation (Table 1). 
Table 1. Seed weight (mg/seed) and water uptake ( $\mu 1 /$ seed) by P. juliflora seed at varying periods

\begin{tabular}{|c|c|c|c|c|c|c|c|c|c|c|c|c|}
\hline \multirow{2}{*}{ Parameter } & \multicolumn{12}{|c|}{ Time after incubation (hr) } \\
\hline & $\mathbf{0}$ & 1 & 2 & 3 & 4 & 5 & 6 & 12 & 18 & 24 & 48 & 72 \\
\hline $\begin{array}{c}\text { Mean seed } \\
\text { weight }\end{array}$ & $29.1 \mathrm{c}$ & $29.22 \mathrm{c}$ & $29.33 c$ & $30.17 \mathrm{c}$ & $30.16 \mathrm{c}$ & $30.48 \mathrm{c}$ & $30.88 \mathrm{c}$ & $31.12 \mathrm{bc}$ & $31.68 \mathrm{abc}$ & $33.72 \mathrm{ab}$ & $34.16 \mathrm{a}$ & $34.48 \mathrm{a}$ \\
\hline S.E. $( \pm)$ & \multicolumn{12}{|c|}{0.908} \\
\hline $\begin{array}{c}\begin{array}{c}\text { Mean WU } \\
\text { (imbibition) } \\
\text { /seed }\end{array} \\
\end{array}$ & - & $0.12 \mathrm{c}$ & $0.23 \mathrm{c}$ & $1.08 \mathrm{c}$ & $1.06 \mathrm{c}$ & $1.38 \mathrm{c}$ & $1.78 \mathrm{c}$ & $2.02 \mathrm{c}$ & $2.58 \mathrm{bc}$ & $4.62 \mathrm{ab}$ & $5.06 \mathrm{ab}$ & $5.38 \mathrm{a}$ \\
\hline S.E. $( \pm)$ & \multicolumn{12}{|c|}{0.916} \\
\hline C.V.\% & \multicolumn{12}{|c|}{$6.51 \%$} \\
\hline
\end{tabular}

Means followed by the same letter (s) are not significantly different according to Duncan's Multiple Range Test.

Table 2. Percentage of germination (G) and germination rate (GR) at different days after incubation (DAI)

\begin{tabular}{|c|c|c|c|c|c|c|c|c|c|c|c|c|c|c|}
\hline \multicolumn{10}{|c|}{ Time after incubation (days) } \\
\hline Parameter & 1 & 2 & 3 & 4 & 5 & 6 & 7 & 8 & 9 & 10 & 11 & 12 & 13 & 14 \\
\hline GR/day & 1 & 2 & 1 & 1 & 2 & 7 & 4 & 4 & 10 & 3 & 2 & 5 & 2 & 4 \\
\hline$\%$ GR/day & 2 & 4 & 2 & 2 & 4 & 14 & 8 & 8 & 20 & 6 & 4 & 10 & 4 & 8 \\
\hline$\%$ G & 2 & 6 & 8 & 10 & 14 & 28 & 36 & 44 & 64 & 70 & 74 & 84 & 88 & 96 \\
\hline
\end{tabular}

\section{Germination and Germination Rate}

Seed germination $(\mathrm{G})$ progressively increased with the incubation period. Germination increased slightly during the first 5 days (14\%). A surge in germination (44\%) was displayed during the period 6-8 days after incubation (DAI). On day 9 , another surge in germination occurred (64\%) and, then germination gradually increased during the rest of the incubation period (70-96\%; Table 2). GR was inconsistent and low during the first 5 days of incubation (2-4\%). There was a surge in the GR on day $6(14 \%)$, which declined on day 7-8 (8\%). The highest GR (20\%) was attained 9 DAI. An inconsistent sharp decline in the GR commenced during the rest of the period (4-10\%; Table 2).

\section{Effect of Sowing Depth on Seed Germination and Seedling Emergence}

Seeds placed on the soil surface or buried at depth below $10 \mathrm{~cm}$ failed to germinate. However, seeds were able to germinate at a burial depth of $2.5-10 \mathrm{~cm}$. At these depths, germination decreased with increased depth. Seeds buried $2.5 \mathrm{~cm}$ deep, displayed complete germination (100\%). At this depth 50,85 and $100 \%$ of the seeds germinated 1,2 and 3 days after planting (DAP), respectively. Seeds planted 5 $\mathrm{cm}$ deep displayed 30, 45, 65 and $75 \%$ germination at 2, 3, 4 and 5 DAP, following the same order. Seeds buried $7.5 \mathrm{~cm}$ deep resulted in 10,20, 40, 50 and $60 \%$ germination at 2, 3, 4, 5 and 6 DAP, respectively. However, at $10 \mathrm{~cm}$ planting depth $10 \%$ germinated after 3 days, $25 \%$ after 4 days, $35 \%$ after 5 days and $40 \%$ after 6 days (Fig. 1).

Emergence (SE) was observed at 2.5 and $5 \mathrm{~cm}$ planting depth only. At $2.5 \mathrm{~cm}$ planting depth, 35 and $75 \%$ of seedlings emerged within 1 and 2 DAP. Complete SE was observed one day later. At a burial depth of $5 \mathrm{~cm}$, SE was $15 \%$ and $50 \%$ at 3 and 7 DAP, respectively (Fig 2).

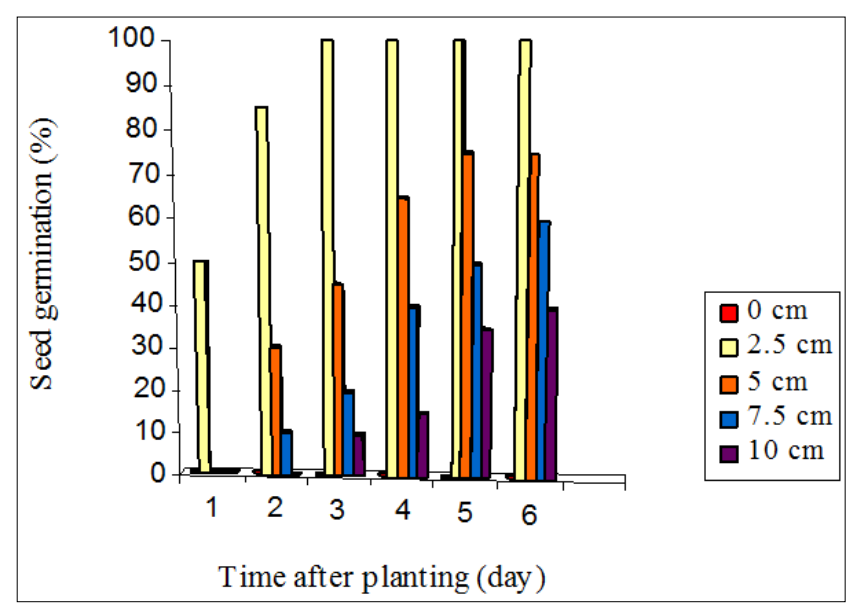

Figure 1. Effect of sowing depth on seed germination

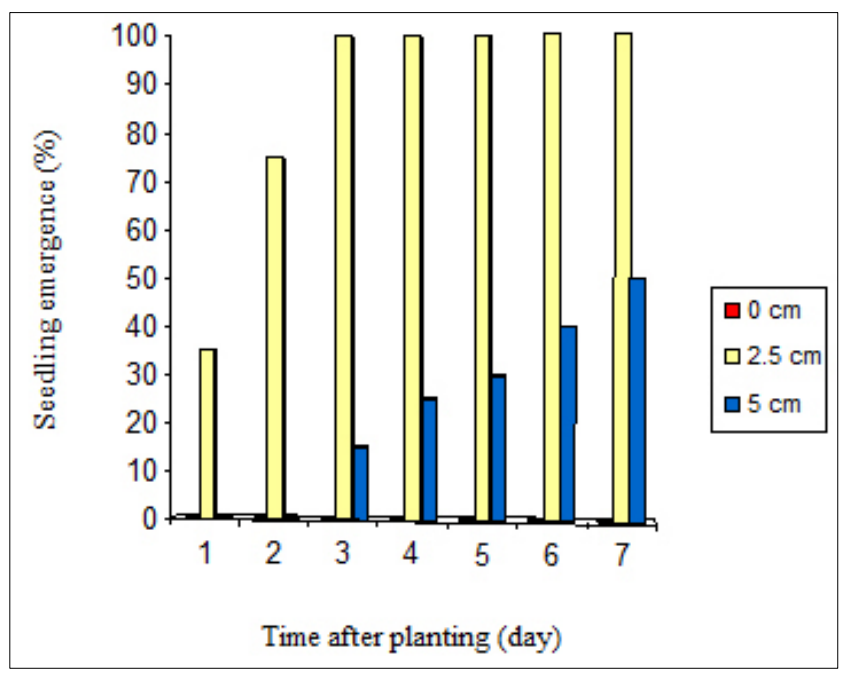

Figure 2. Effect of sowing depth on seedling emergency 


\section{Effect of Acid Scarification and Sheep Feeding on Seed Germination and Seedling Emergence}

$P$. juliflora seeds treated with sulfuric acid $(60 \% \mathrm{v} / \mathrm{v})$ for 5 min. displayed very rapid seed germination as 50,90 and $100 \%$ germination was achieved after 1,2 and 3 days of incubation, respectively. Germination of untreated seeds was initiated one DAI (5\%), increased to $20 \%$ on the second day, amounted to $65 \%$ at $9 \mathrm{DAI}$ and remained constant for the rest of the incubation period. Differences in germination between scarified seeds and untreated ones were significant $(\mathrm{P}=0.05)$ (Fig. 3). SE of acid scarified seeds was rapid as $45 \%$ of the seedlings emerged 3 DAP and complete emergence commenced one day later. SE from untreated seeds was also initiated 3 DAP and was low $(10 \%)$ at 6 DAP. SE progressively increased from 20 to $65 \%$ during the period 7-13 DAP. The differences in SE between acid scarified seeds and the control were significant $(\mathrm{P}=0.05)$ (Fig. 4).

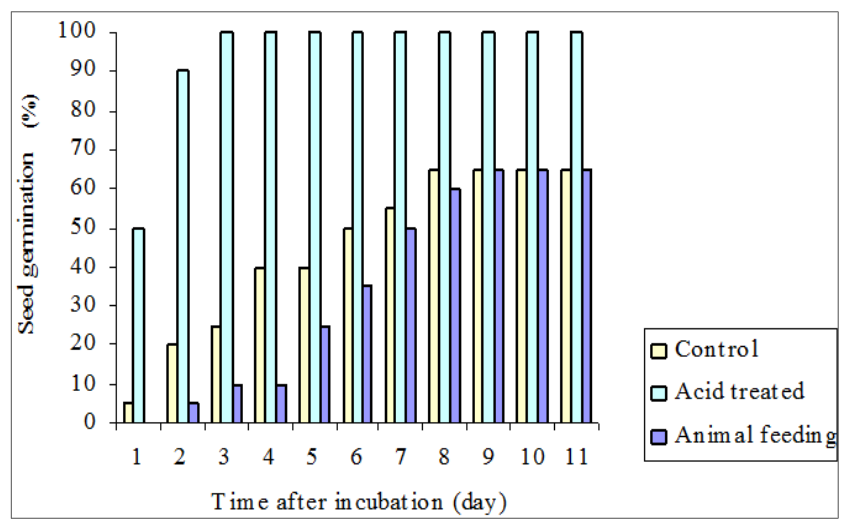

Figure 3. Effect of seed treatment on seed germination

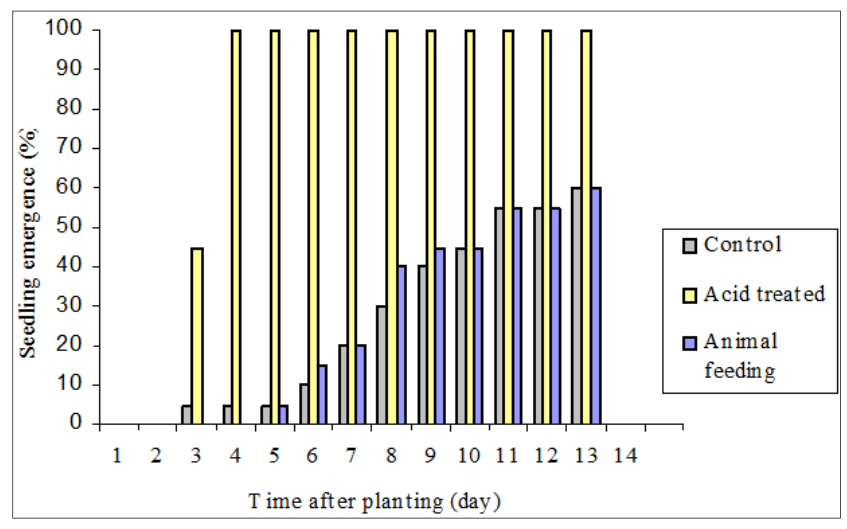

Figure 4. Effect of seed treatment on seedling emergency

Germination of seeds extracted from sheep droppings and untreated seeds was initiated 1-2 DAI. Germination progressively increased with incubation period for up to 8 days, and no further increase was recorded during the rest of the incubation period. During the first 6 days of incubation, untreated seeds resulted in higher germination than those extracted from sheep droppings. However, germination was similar during the rest of the incubation period (50-65\%). During the first 6 days of incubation, germination of seeds extracted from sheep droppings ranged from 5-35\%, while germination of untreated seeds ranged from 5-50\%. Differences in germination between seeds extracted from sheep droppings and untreated ones were not significant $(\mathrm{P}=0.05)$ (Fig. 3).

Seedlings from seeds extracted from sheep droppings started to emerge 5 DAP, while SE of untreated seeds was initiated 3 DAP. SE of both treated and untreated seed was low $(5-20 \%)$ during the first 7 DAP. A surge in SE was witnessed 8 DAP, especially in seeds extracted from sheep droppings ( $c a .40 \%)$. Emergence progressed at a lower rate later. SE from seeds extracted from sheep droppings was higher than that of the control during the period 6-9 DAP, but emergence was almost similar later on. Differences in SE between seeds extracted from sheep droppings, and the untreated seeds, were not statistically significant $(\mathrm{P}=0.05)$ (Fig. 4).

\section{Discussion}

The results of the present investigation revealed that intact $P$. juliflora seeds imbibed very limited amounts of water when soaked in water for up to $18 \mathrm{hr}$. However, imbibition was high during the period 24-72 $\mathrm{hr}$. Uptake of water is essential for activation of seed metabolism. Metabolic activity provides the necessary energy for embryo growth ${ }^{[12]}$. These findings suggest that dormancy in $P$. juliflora is imposed mainly by the seed coat. Coat imposed dormancy is of wide occurrence in legumes and has been reported as a major characteristic governing their weediness ${ }^{[12]}$. The importance of seed coat imposed dormancy in $P$. juliflora is further substantiated by the increase in germination and water uptake following pre-soaking in sulfuric acid $(60 \% \mathrm{v} / \mathrm{v})$ for only five min. This treatment damaged the seed coat and permitted water entry resulting in $100 \%$ germination. Such results are in agreement with those obtained by Johanston et al. for hemp Sesbania (Sesbania exaltata (Rnf) Cory) ${ }^{[13]}$, Ali for Sesbania arabica Steud ${ }^{[12]}$, Eastin for Drummond Rattlebush (Sesbania drummondii Durand Oak) ${ }^{[14]}$ and Mohammed for mesquite ${ }^{[15]}$..

Under favorable conditions, germination of $P$. juliflora seeds was very rapid, and was initiated one DAI. It progressively increased with time and reached $96 \%$ within two wk. Germination rate was maximum (20\%) 9 DAI. It is for these reasons the plant is a successful noxious weed, and is at present infesting large tracts of the irrigated and rain fed areas in the Sudan.

On the other hand, $P$. juliflora seeds pass through the digestive system of grazing sheep, goats, cows ( $>100$ million heads) and possibly other animals, unchanged. However, this might lead to their dissemination for long distances. Results revealed that seeds collected from sheep's droppings were free from the pericarp and displayed $65 \%$ germination and $60 \%$ emergence. Such results are in agreement with those obtained by Ali for S. arabica $^{[12]}$ and Mohammed (2001) for mesquite. 
$P$. juliflora seeds failed to germinate when placed on the soil surface. This indicates that germination is possibly inhibited by light and inadequate moisture that prevail on the soil surface. However, seeds can germinate from soil depths up to $10 \mathrm{~cm}$, but the highest germination and emergence were encountered at $2.5 \mathrm{~cm}$. Germination and emergence at this depth were very rapid, and were initiated one DAP. This suggests that the soil seed bank will always contain seeds of $P$. juliflora ready to germinate when moved to a shallower depth by agricultural implements.

\section{REFERENCES}

[1] Elfadle MA \& Luukkanen O. 2006. Field studies on ecological strategies of Prosopis juliflora in a dry land ecosystem, Journal of Arid Environment, 66 (1): 1-15.

[2] Simpson BB. 1977. Mesquite, its biology in two desert scrub ecosystems. Dowden, Hutchinson \& Ross, Inc. Stroudsburg, PA.

[3] Zeven AC \& Zhukovsky PM. 1975. Dictionary of cultivated plants and their centres of diversity. Centre for Agricultural Publishing and Documentation, Wageningen, Netherlands.

[4] NAS. 1980. Firewood crops. Shrub and tree species for energy production. National Academy of Sciences, Washington, DC.

[5] El fadl MA. 1997. Management of Prosopis juliflora for use in Agroforestry system in the Sudan. Academic dissertation for the Dr. Sc. (Agric. and For.) degree, University of Helsinki. Helsinki, Finland. Pp. 101.
[6] Catterson T. 2003. USAID strategic integrated plan in Sudan, 2003-2005 environmental threats and opportunities assessment. USAID/REDSO/NPC and the USAID Sudan Task Force. Washington, March 2003.

[7] Sudan Update. 1997. Desert tree is a victim of its own success. Sudan Update: 8 (22): 11-97.

[8] El-Keblawy A\& Al-Rawai A. 2007. Impacts of the invasive exotic Prosopis juliflora (Sw.) D.C. on the native flora and soils of the UAE. Plant Ecol 190: 23-35.

[9] Rout M \& Callaway RM. 2009. An invasive plant paradox. Science 324: 734-735.

[10] Inderjit WDA, Karban R\& Callaway RM. 2011. The ecosystem and evolutionary contexts of allelopathy. Trends Ecol Evol 26: 655-662.

[11] Morgan MA. 1991. Studies on Xanthium strumarium Biology and Control in Sudan Gezira. M.Sc. thesis, University of Gezira, Wad Medani, Sudan.

[12] Ali AM.1998. Factors Affecting Sesbania arabica Seed Imbibition, Germination, and Emergence. M.Sc. thesis, University of Gezira, Wad Medani, Sudan.

[13] Johanston SK, Walker RH \& Murray DS. 1979. Germination and emergence of Hemp Sesbania (Sesbania exaltata). Weed Science 27 (3): 290-293.

[14] Eastin,E.F. 1984. Drummond rattlebox (Sesbania drummondii) germination as influenced by scarification, Temperature, and seeding depth. Weed Sci. 32:223-225.

[15] Mohammed AA. 2001. Some aspects of Germination, Dormancy and Allelopathy of Prosopis juliflora (Mesquite). M.Sc. thesis, University of Gezira, Wad Medani, Sudan. 